\title{
A Glimpse From Behind the Mask: Thoughts from the Old Clinician
}

Strauss DW*

210 Price Street, Walterboro, SC 29488-3229, USA

*Correspondling author: Donald W Strauss, 210 Price Street, Walterboro, SC 29488-3229, USA

Received: J une 23, 2021; Accepted: August 04, 2021;

Published: August 11, 2021

\begin{abstract}
This is an article/essay with focus on the question of the conflict between professional mystique and transparency in the clinician-patient relationship.

Implied is the assumption that the professional "mask" influences treatment outcome and can distort or enhance the genuine nature of the relationship between those being served and those who serve them.

The simple purpose of the question asked in the article is to stimulate discussion as to the relative utility of the professional mystique and professional transparency as to the degree that each influences treatment outcome and clinician satisfaction.
\end{abstract}

Keywords: Glimpse; Transparency; Professional

\section{Short Communication}

You might wonder in the age of complex and multi-layer healthcare delivery systems why an essay that relates to individual transparency would be worth your time to read. My answer is in the form of a question: should one aspire to be a hyper-competent technical provider of service or a person with competent skills who aspires to be a healer for those we serve.

I like the term professional intimacy: having an intimate knowledge of and investment in the life and health of patients. The question to be asked is do professional boundaries require rigid barriers to person-to-person connection and interaction?

Fifty years ago when I just began to practice that I thought introducing myself as Dr. Strauss was pretentious and off-putting. What I found is that to introduce myself as Don Strauss instead of promoting equality was a failure on my part to establish my appropriate position in the relationship; it made the patient anxious rather than at ease as I had hoped. I learned that in a person-to-person relationship it is important to establish a sense of who the players are and what their roles are in the relationship. Does that dictate that we practice in a cloak of mystery to regulate the appropriate distance between patient and clinician? Does "lifting the mask" equate going naked before the patient?

The simple question that I hoped this essay provokes is one that asks if the clinician or the patient are better served when the "mask" is more or less firmly in place.

Like most essays, this writing is subjective and intended to provoke thought and feelings rather than reach a conclusion.

When I was in training a half century ago one of the "pearls of wisdom" that was passed on at least a half dozen times that one should never display pictures of one's family in an office as that promotes an undesirable level of intimacy. Today this appears a bit dated and over the top but the underlying message seems well in place today.

Growing up in the Deep South in the 1950s I yearned to be Dr.
Harry Jacobson. Dr. Jacobson, now decades dead, was the wellexperienced, all-purpose physician in our community. He owned an enormous black Cadillac always the latest model. He had a driver who was ever present to take him to the hospital, his office, on house calls, and where ever he wished to go.

Long before urgent care venues dominated the minor illness and injury market, family doctors often saw after their patients by making house calls. When our home was visited by illness Dr. Harry would make a late afternoon house call to tend to the afflicted person. When he entered our house, always with a cigar in hand he was accorded all the courtesy and honor of visiting royalty. He was treated as though he was our personal deity. Dr. Harry was a man well known and respected in all corners of the community. The consensus was that he was a prince among men.

Sadly, as time passed, it became clear to me that evolving into a Dr. Jacobson clone was not as desirable as I had once believed. What I became aware of was that he practiced in a vacuum and neither he nor his practice was examined, weighed and evaluated. He invited no external peer review. He was not a devotee of continued medical education. His patients, who for the most part stood in awe of him, were highly unlikely to question or challenge a man of his education and stature. Over a career, no one was keeping track of his treatment "wins and losses".

His unmarred professional persona was held in place, for the most part, by an unspoken collusion between Dr. Harry and his patients, aimed at the continuation of a sense of security and wellbeing generated by the maintenance of the status quo. From the vantage point of age, hindsight, and experience, my conclusion is that Dr. Harry was a moderately adequate clinician, but not a great one. He appeared to excel as a medical showman more than a dedicated healer. He was responsive to his patient, and probably meant well. Even as a young person, I wondered, certainly would not have spoken of my thoughts out loud, of his many year practice of performing eight tonsillectomies a week in his office with only the assistance of his receptionist. 
I am drawn to the question of who are we and who do patients believe we are. How much of the cloak of professional mystique is necessary to keep the patient's trust?

How much of our camouflage of who we are is to protect the patient and how much is to protect ourselves?

Graduation ceremonies are not high on my list of fun pastimes. I confess that I rarely remember the keynote speaker's message for the entire drive home. Several speakers stand out because they are humorous or the speaker spoke for a particularly short time. The one exception was a talk neither humorous nor short, but was remarkable as a source of horrific advice. The speaker was a physician highly esteemed for his academic knowledge and his clinical prowess. His address to the newly minted doctors regarded a position as to why one should never purchase malpractice insurance.

His advice was to make every patient feel that you are "his best friend even if you loathe them". With this established "friendship", even clearly iatrogenic harm would have no negative impact on the clinician as your "best friend" would be unwilling to take legal action against his "good personal friend and physician."

My hope has always been that the graduating students were as inattentive to this commencement message as is usually the case. What he suggested was a strategy that was reliant on never lifting the mask, which would markedly reveal the duplicity of his this relationship.

I witnessed a tragic event that vividly and powerfully addressed the inequality that patients often feel between who they believe they are and who the patient believes the practitioner to be. In the time prior to the advent of trauma centers, emergency rooms handled any and all medical crises that randomly came through the door. I worked in an Emergency Room which had a sense of notoriety as this was the location where Dr. Martin Luther King, Jr. was taken and died after being shot in Memphis.

Three miles north of our hospital, a massive chemical plant was being constructed. Workers were employed for all three shifts; I would imagine to meet a construction deadline. At 3:16 a.m. on a Sunday an explosion and fire for which the workers were unprepared damaged an area of the construction in which five workers were injured. All five were transported by a company truck with no first aide being attempted to our Emergency Room.

The four of us staffing the ER were totally overwhelmed. We triaged the workers and quickly sought re-enforcements from other floors in the hospital. We divided into teams and each team focused on one patient. My team attended a middle aged man who was the most severely injured. Given the state of the art and our skill level, his injuries were blatantly incompatible with survival. We tried everything we could think of in a frantic effort to deny the inevitable. At just over three hours we knew that he had lost the battle.

His last words to us, which continued to resonate for me, were "I am sorry to cause so much trouble to all of you in the middle of the night like this". "I know you must be busy and tired and did not need me to make such a mess."

His perception of who we are under the mask put us high on the hierarchy list of people and him so low as to need to apologize to us for dying in our Emergency Room. The distance between the practitioner and the patient born of the perception of who each of us are in this case was so powerful as to evoke a sincere apology from this dying man.

I wonder what prior experience with a healer "behind the mask" led to this final "doffing of his cap" as he was occupied in the final stage of dying.

We have as clinicians generated a mythology and many errors as to whom we are through providing a paucity of information about who we are for the patient to utilize in whatever manner is helpful to them.

Transparency is a watchword of this era. Our society has, on multiple layers, slowly moved toward the goal of increasing accessible transparency. Observably, clinicians have even more rapidly moved away from this goal and practices that would support it. I have an excellent internist who I see for a scheduled appointment twice yearly. I call him my "well doctor" as I only see him when I am in good health. $\mathrm{He}$ is tightly scheduled in 15 minute blocks as are his colleagues and most group practices. Like a multitude of health care consumers, if I am in any acute distress, I will not fit into the scheduled time so I must be shifted to an urgent care facility or Emergency Room.

One enters these settings armed only with faith that good and appropriate care will be provided. The "professional mask" is a prominent and pervasive core character of these short term settings. So completely is the professional camouflage as to obscure any trace of person to person interaction. Concealed are even the basic details of who the provider is: training, experience, skill set, or a single thread of who the healer behind the mask might be as an authentic person. Any semblance of a relationship between the clinician and the individual seeking service, cannot bear fruit with the information drought that exists.

As society appears to move slowly in the direction of transparency, health care has moved rapidly toward anonymous clinicians who care for patients in whom they often have little investment and will perhaps never see after one encounter. We seem to be going the wrong way.

A comedy of errors can easily develop when neither the patient nor the clinician knows who the other is as a living, breathing human. I watched this play out over a six week period that was avoidable with a fifteen minute, genuine person to person conversation.

The patient was an 86 year old man who had a cervical fracture from an early morning fall after an all-night card game. He had reared and educated his children, and supported his family with a comfortable living with the proceeds from his winnings as a professional gambler. Through his career path this was the only occupation in which he worked for his entire working life.

The protocol of the day utilized Crutchfield tongs, continued traction, six week confinement to bed, and a three day observation in a premium room.

All would have been well if he had hospital insurance, an acceptable and verifiable income, or a significant asset pool; he had none. He was admitted with the clothes he was wearing, a small suitcase, and an oversized worn and battered briefcase. 
In the normal course of events, he would have been moved to the less comfortable "charity" ward and the attending physician who had been caring for him would have handed his care over to the first year orthopedic resident.

The difficulty with the plan was, he refused to participate in a relocation. His demeanor appeared to be somewhat threatening, which was effective in keeping the hospital powers at bay.

The hospital administration believed that they would lose six weeks revenue generated by private room occupancy. The fee for service clinician could not ethically terminate care unless he was moved to the resident staffed, "charity" floor leaving the clinician to believe that they would be in danger of providing six weeks of free service. In this impasse both the care providers and the patient played roles that were not representative of who they actually were as people.

At that time I was working solo as the 10:00 pm to 8:00 am surgical technician at a faith based community hospital. Other than a few emergency surgeries I was unoccupied until 6:00 am when the daily surgery schedule began. Having chronic shpilkes, I spent most of my spare time roaming the hospital looking for entertainment. This patient was awake on my shift, sleeping during the day and always up for a chat. He had a never exhausting repertoire of interesting stories so I became well acquainted with him during his six week hospital stay. I was a well-informed silent spectator to his conflict with the hospital establishment.

The patient was a charming, gregarious man who would have easily adapted his stance had he received goodwill from the caregivers. He was skeptical as to who these "fast talking people" actually were. He complained that often the people who are approaching him did not clearly identify their role or what part they played in the proposed move.

The hospital staff, in a behavior pattern that was reminiscent of Gandhi or perhaps Neville Chamberlain, approached the patient in ever more conciliatory measures and friendly terms. All this while experiencing growing anger and frustration.

The patient in part attributed professional success to his ability to read non-verbal cues. He was sure that he did not know who these people actually were, but was sure that who they presented themselves to be was not accurate.

Six weeks passed; he recovered well and was given a discharge date. I was invited to be his guest at what he termed his "final performance" as a patient. His last hour in the hospital was the most remarkable of all. This was the era before inpatient care had become astronomically expensive. When he was discharged the "damage" as he called it was $\$ 28,210$. He gave a quick look at the statement; I think more for effect than review. He reached in his battered briefcase that had been in his room through all his stay and extracted a large stack of hundred dollar bills from among identical stack of bills and counted out $\$ 30,000$ in cash $\$ 28,210$ for the charges and the remainder as he said it was a tip for good service.
He told me that it was all a gamble. If he recovered, as he had, he would make payment in full. If he died, his son would collect his belongings including his briefcase and the hospital and doctors would not be paid.

It was a win-win situation; he lived and the hospital is paid.

If the parties involved had allowed each other the transparency to see who they actually were as people, then the issue could have been resolved over a cup of coffee.

Sometime in the mid-1970s, I was spending a week in a rural community 60 miles north of Memphis. In the interest of family peace and harmony, I was evaluating patients in a long term care facility. My brother-in-law was the CEO of the hospital complex that housed the care unit. The vicious hounds of the regulatory agency were closing in on him for unmet bureaucratic requirements.

Because of the bureaucratic fueled crisis, the emphasis was on work volume rather than work quality. I was meeting my task with more of a "lick and a promise" than would usually be the case. I thought that remaining the most concealed behind the professional mask would be the most efficient way to meet the deadline. This definitely was not my favorite vacation of all times.

Deficits and symptoms were all I ever knew of the residents of this care facility with the exception of one man. He was dressed as a farmer in faded overalls, farm boots, and a sun-bleached International Harvester hat. He was always near the unit door and gave the appearance of a farmer on the verge of returning to the field. His demeanor was always upbeat and cheerful. Whatever impairment he might have was not readily apparent to me. Each morning, we exchanged pleasantries, the weather report, and the closing value of soybeans on the Chicago commodities market that day. I went about my business and he resumed his post near the door.

One morning I deviated from the routine, perhaps motivated by the realization that I had done nothing to officially evaluate this gentleman. I asked him to remember a series of numbers that I would ask him to recite three minutes later. I always use my social security number for the purpose to assure that I would recall the numbers myself. He was up for the task and seemed to enjoy a challenge.

As is often the case, I was distracted by other patients and totally forgot to ask him about the numbers. At the end of a long day, I again encountered the farmer at the door. He pleasantly greeted me and asked when I was going to "test him on the numbers". I was, for the moment, at a total loss as to what he was asking. He kindly and gently reminded me of giving him numbers to remember and then flawlessly recited my social security number. With a hint of a smile, he offered me some advice "boy, you best be careful about forgetting like that, or you will find yourself in a place like this". No professional mask, just two people laughing together.

One additional thought. From 1933 to 1981, for professional reasons, even the Lone Ranger dropped his mask seven times. 